Human Revolution. Paul Mellars and Chris Stringer, eds. Pp. 232-244. Edinburgh: Edinburgh University Press.

$1989 \mathrm{~b}$ Documenting the Origin of Modern Humans. In The Emergence of Modern Humans. Erik Trinkaus ed. Pp. 6796. Cambridge: Cambridge University Press.

1992a Reconstructing Recent Human Evolution. Phil. Trans. of the Royal Soc. B.337:217-224.

1992b Replacement, Continuity and the Origin of Homo sapiens. In Continuity or Replacement: Controversies in Homo sapiens Evolution. Günter Bräuer and Fred H. Smith. eds. Pp. 9-24. Rotterdam: Balkema.

Thorne, Alan G., and Milford H. Wolpoff

1992 All About Eve. Scientific American 267(3):6.

Trinkaus, Erik

1981 Neanderthal Limb Proportions and Cold Adaptation. In Aspects of Human Evolution. Chris B. Stringer, ed. Pp. 187224. London: Taylor and Francis.

1992 Morphological Contrasts between the Near Eastern Qafzeh-Skhul and Late Archaic Samples: Grounds for a Behavioral Difference? In The Evolution and Dispersal of Modern Humans in Asia. T. Akazawa, K. Aoki, and T. Kimura, eds. Pp. 277-294. Tokyo: Hokusen-Sha.

Van Vark, Gerrit N., and Alan Bilsborough

1991 Shaking the Family Tree. Science 253:834.

Waddle, Diane

1993 The Evolution of Modern Humans: Testing Models of Modern Human Origins Using Matrix Correlation Methods. Ph.D. thesis, SUNY Stony Brook.

Webb, Stephen

1990 Cranial Thickening in an Australian Hominid as a Possible Palaeoepidemiological Indicator. American Journal of Physical Anthropology 82:403-412.

Wolpoff, Milford H., Xinzhi Wu, and Alan G. Thorne

1984 Modern Homo sapiens Origins: A General Theory of Hominid Evolution Involving the Fossil Evidence from East Asia. In The Origins of Modern Humans. Fred H. Smith and F. Spencer, eds. Pp. 411-483. New York: A. R. Liss.

Wolpoff, Milford H., Alan G. Thorne, Jan Jelínek, and Yinyun Zhang

1991 The Case for Sinking Homo erectus: 100 Years of Pithecanthropus is Enough! Abstracts Conference 100 Jahre Pithe- canthropus--das Homo erectus Problem. Frankfurt.

\section{Getting It Straight}

\author{
DaVid W. Frayer \\ Department of Anthropology \\ University of Kansas
}

MILFORD H. WOL.POFF

Department of Anthropology

University of Michigan, Ann Arbor

AIAN G. THORNE

Department of Prehistory

Australian National University

FRED H. SMITH

Department of Anthropology

Northern Illinois University

Geoffrey G. Pope

Department of Anthropology

William Paterson College

The old theory, claiming that man evolved exclusively from one center whence he spread over the Old World each time afresh after having entered a new phase of evolution, no longer tallies with the palaeontological facts. [Weidenreich 1940:381]

We have puzzled over why this long-lasting debate about modern human origins has been so intense. The content and tone of this reply to our $A A$ article suggest some answers to this question. We address these below, as well as the individual comments made about our work. This reply does not include all our disagreements with Stringer and Bräuer's comment or with their other publications; but in response to their unacceptable assumption that specifics of their publications that we do not criticize can be taken as areas of agreement with them, we will try to address as many details as possible.

\section{The Muddle in the Middle}

One of our colleagues is particularly concerned that established and experienced paleoanthropologists seem to draw such different conclusions from the same data. While it is certainly not the first time this has occurred, we believe this debate can shed some light on how this happens. In this exchange we have found that there are three reasons why controversy persists over modern human origins. 
Confusion about the Theory the Eve Theorists Are Defending

The definition of the Eve theory is clear and unambiguous, as stated in the classic Stringer and Andrews article (1988a). To quote Stringer's definition (1989:122) in a publication where he describes the theory and cites Bräuer as one of its sources:

Many recent proponents of this model have suggested Africa as the probable continent of origin of Homo sapiens, with an early Late Pleistocene origin for the species and an initiation of African regional differentiation, a subsequent later Pleistocene radiation from Africa, and a final establishment of modern regional characteristics outside of Africa.

They write of the intensity of their support for the Eve theory in no uncertain terms (in this and all subsequent quotations, the boldface in quotes is ours):

Although we feel that an African origin for Homo sapiens is highly probable, the exact time, place, and mode of origin of the species cannot yet be determined. [Stringer and Andrews 1988a:1267]

I cannot at present recognize any unequivocal facts which would disprove even a global 'Out of Africa' model. [Bräuer 1989:148]

However, this is no longer the Eve theory that Stringer and Bräuer defend, and according to them it never has been. Bräuer now maintains:

The extreme 'Out of Africa' model, which assumes that modern humans represent a different species than Neandertals and other archaic humans and that little or no hybridization took place between the latter and dispersing modern humans from Africa, is regarded even by its authors as merely a test model. [1993:404]

Stringer now describes his article with Andrews as follows:

My co-authorship of a controversial paper in Science supporting the "Out of Africa" model for $H$. sapiens origins was not intended to imply that there was no evidence against the model or no problems with the supporting palaeontological and genetic evidence cited. [1992a:10]

In this reply they now say they support a "recent African origins" hypothesis, and they "do not feel that the Eve concept ... is a very useful way of characterizing" it. We would normally encourage a change of mind on this issue, but in denying that they ever supported the Eve theory, they lose the opportunity to explain where and why their minds have changed. Besides creating unnecessary confusion for those who have followed the debate, this leaves us uncertain about which of their ideas we should test.

\section{Confusion about the Theory the Eve Theorists Are Attacking}

Simply put, Stringer and Bräuer do not seem to understand the theory that they are so convinced is incorrect. When one of the authors first addressed multiregional evolution, he wrote:

Under the multiregional model the marked morphological and metrical similarities of these geographically distinct crania [P'redmostí 3, Zhoukoudian Upper Cave 101, Mladeč 1 , and Zhoukoudian Upper Cave 103] are explained as the result of parallel evolution from distinct Middle Pleistocene ancestors. [Stringer and Andrews 1988a:1266]

But as stated in a number of places, multiregional evolution is the antithesis of parallel evolution. Common trends throughout the species are explained by genic exchanges and common selection, acting on gene pools distinguished mainly by allele frequency differences. When this clarification was brought to their attention (Wolpoff et al. 1988), the response was "some of the predictions are evidently not welcomed by proponents of the model" (Stringer and Andrews 1988b:774).

Then in 1990 Stringer erroneously distinguished between a different interpretation of the multiregional model and "the gene-flow, or hybridization, model [which] traces modern populations back to a web of ancient lineages whose genetic contributions varied from region to region" (1990:98). This is confusing because it is precisely the way Wolpoff, Wu, and Thorne (1984) have perceived and outlined the mechanisms of multiregional evolution on numerous occasions. For instance, in 1984 they described gene flow as "the latticework that connects populations of a polytypic species" (Wolpoff, Wu, and Thorne 1984:461). Dropping this contention, Stringer recently asserted: "If we can turn away from a universal multiregional model for modern human origins, we cannot so easily exclude a dual African and East Asian ancestry model" (1993:222-223). But what is this "universal multiregional model"? It is certainly nothing we ever wrote about. 
Bräuer (1992) seems equally confused, since he asserts that features displaying regional continuity do not show that there was regional continuity.

Regional evolution ... does not necessarily reflect regional evolutionary changes caused by local selection and/or drift and gene flow (Wolpoff 1989), but merely the common presence of certain features which could just as well be explained by gene flow between archaic and immigrant modern populations [to help the reader, Bräuer uses gene flow in two different ways in this citation, the second use seems to mean "admixture"]. [1992:92]

With evidence of ancestry not acceptable for corroborating regional continuity, one wonders if Bräuer is focusing on a methodology that allows the disproof of what he regards as the alternative explanation, the Protsch/ Bräuer theory of African origins. Not so, since he further maintains "it would hardly be possible to provide concrete evidence of typically African features among early modern humans in Europe and Asia" (Bräuer 1992:89). This approach provides a unique challenge for those concerned with the philosophy of scientific methodology, especially as applied to the criterion of falsification.

Singly or together Stringer and Bräuer continue to construct one after another "multiregional evolution hypothesis" in a form they can disprove instead of trying to disprove the hypothesis originally advanced. In this reply they still characterize multiregional evolution as requiring "long-term, substantial, interregional gene flow," that "this approach accepts that all Pleistocene hominids . . . are ancestral to modern Homo sapiens," and that "it is unclear whether regional continuity features were supposedly being maintained through drift or selection."

Each of these characterizations is incorrect, and we ask the reader to examine some published comments on these issues:

We take no position on the issue of magnitude [of gene flow]; both large and small magnitudes for various species have been reported. Moreover, while the gene flow reported between adjacent human populations is usually anything but minuscule, we admit the possibility that this magnitude may be lower in other species, or in human prehistory.... It is our contention that over geologic time, this issue is irrelevant because genetic comparisons between human populations, or between humans and the African apes, show that the actual mag- nitude of genetic change to be accounted for during the evolution of Homo is surprisingly small. [Wolpoff, $\mathrm{Wu}$, and Thorne 1984:459]

The mtDNA data are consistent with a model of restricted but recurrent gene flow throughout the entire time period marked by the time to coalescence. ... The nuclear DNA pattern [also] only clearly offers support for restricted gene flow among Old World human populations. [Templeton 1993:69]

[Our] view traces all modern populations back to ... a web of ancient lineages whose genetic con tributions to the present varied from region to region and from time to time. [Frayer et al. 1993:17; here, in claiming that all populations have fossil ancestors, we did not imply that every fossil left descendants]

Regional differences were maintained through a series of balances between (1) genic exchanges ... and (2) selection (for some features) and drift (for others). [Frayer et al. 1993:17]

We invite the reader to follow the advice of Stringer and Bräuer and compare our various publications on these topics. While our understanding of the multiregional model has been honed over time and clarified in response to constructive criticism, we have unwaveringly maintained that clinal balances for regional features have involved selection for some features and drift for others, and that our choice of features to illustrate the multiregional pattern avoided those that arose due to environmental adaptation. The distribution of many features may reflect regionality, but our point is that only a few can unambiguously show it.

Stringer and Bräuer just do not perceive the implications of the clinal model that multiregional evolution is based on. For instance, in addressing the issue of whether continuities can be expected according to the Eve theory, they agree "with the proviso that limited hybridization could have occurred which might mimic the effects of in situ evolutionary change." The theory we have developed is based on the balance of genic exchange (read "hybridization" in their terminology) and lo cal selection and/or drift (read "in situ evolutionary change"). As we view evolution, these are not alternative explanations but integral parts of the same normal process. 


\section{Misunderstandings about Popperian Science}

The Stringer and Bräuer response to our article provides a good deal of insight into how they approach science. For instance, they state "no attempt is made to test hypotheses of relationship," but then proceed to criticize our testing a specific hypothesis of relationship dictated by the Eve theory-our resolution of the trichotomy of WLH 50, Ngandong, and LH 18.

A deeper problem is in their misunderstanding of the Popperian approach and the role of refutation in it. Perhaps most fundamental is their lack of appreciation that all statements of relationship are hypotheses to be tested. Their Eve theory helped develop convincing tests for us by providing an alternative explanation with contradictory predictions. The failure of this theory, as we have persistently stated, renews focus on finding other means of testing the multiregional hypothesis. It does not prove it to be true.

We find that they misunderstand the significance of this. For example, Bräuer wrote:

It is incorrect for proponents of the Multiregional Evolution model to believe that specific indicators of a certain degree of continuity will provide support for their model while simultaneously helping to refute the replacement view. [1992:84]

But what, besides the observations of continuity in many places, could possibly support multiregional evolution? What besides that very continuity, when there is supposed to be discontinuity caused by African replacement, could better refute the Eve theory?

The point Stringer and Bräuer miss is that science proceeds by refuting theories, not supporting them. When they suggest that we should "compare different lineages and then select the best supported ones," they propose an approach that is the anathema of Popper's. Moreover, their misunderstanding of the role of refutation underlies their precept that we are "selectively choosing our data." In fact, we mean to selectively choose our data as we seek refutatory instances. What good are a thousand evidences in support of the Eve theory if a few clear facts show it is wrong? As Popper wrote, there is much to be said for any theory-what is important is what can be said against it. If this is what constitutes selective presentation of data, we admit that we did it and hereby provide warning that we intend to do it again.

\section{Revisionism: Is Eve a Straw Woman?}

Stringer and Brāuer admit to differences in emphasis in their modern human origins models. Bräuer claims to "favor a greater degree of hybridization between dispersing moderns and resident archaics during the dispersal phase." We welcome this interpretation as it matches much of what we have written on the role of the genic exchange process. However, we have trouble reconciling it with Bräuer's use of mtDNA to support his interpretation.

The results based on mtDNA with its special mode of inheritance and high divergence rate have become an important source of support for the assumption of an African origin of modern humans. [Bräuer 1989:133]

There is no fundamental contradiction between the evidence from DNA and that from the fossil record. [Bräuer 1989:135]

The problem is that the mtDNA evidence he cites describes a replacement process without any admixture at all. As Eve theorists Stoneking and Cann (1989:28) once put it, "the rather staggering implication is that the dispersing African population replaced the non-African resident populations without any interbreeding." While Stringer and Bräuer complain that it is inappropriate to claim that Bräuer holds an extreme view of total replacement, his embracing the mitochondrial data allows no other interpretation. In fact, as long as their theory relies on the mitochondrial evidence, their disclaimer that we set up a straw man by attributing to them an "extreme version of the Eve theory" ignores the fact that it is the only version possible.

\section{Australasia}

Stringer and Bräuer clearly have difficulty in fitting this Australasian sample into their scheme. According to Stringer it "represents the greatest challenge to the Out of Africa model" (1992a:15). WLH 50 poses particular problems since, as we have repeatedly argued, much of its anatomy mirrors that found at Ngandong, including a number of seemingly unique features that track well beyond the Ngandong material. In 1988 Stringer accepted WLH 50 as "the only credible morphological intermediate between middle Pleistocene Indonesian hominids and the late Pleistocene Australians" (Stringer and Andrews 1988a:1266), then explained it away through the objectionable assumption that "perhaps Australia was a special case where 
local differentiation, cultural practices, or pathology led in some cases to apparent evolutionary reversals" (Stringer and Andrews 1988a:1267). In this comment the explanation for the anatomy of WLH 50 is reduced to a pathological one. Never mind that the same anatomy is approached as part of the continuous range of variation in the Coobool Crossing specimens or that its expression in the Ngandong remains is not attributed to pathology or to cultural practices. Yet, even as these criticisms are raised, Stringer and Bräuer turn around and seem to accept the normality of the specimen, when complaints begin that we did not compare it correctly to ascertain its place in human evolution. Of course, no comparisons would be appropriate if it were truly pathological.

Stringer and Bräuer complain that in the trichotomy we tested (whether WLH 50 was phenetically closer to a possible Ngandong ancestor or to an African ancestor, as would be expected if the Eve theory were correct), we used Laetoli 18 for comparison to WLH 50 instead of comparing the Australian to Border Cave 1. We might have used Border Cave 1 to illustrate the ancestry enigma, but we chose the Laetoli specimen for formal comparison in order to load the comparison in favor of the Eve theory prediction. Laetoli 18, unlike Border Cave 1, at least retains a low, flattened forehead and supraorbital development. Indeed, Bräuer regards $\mathrm{LH} 18$ as "stand[ing] almost at the threshold to modern humans" (1992:87); therefore, it should be a credible potential ancestor for them.

They maintain that "the use of Omo-Kibish 2 instead of LH 18 would have completely changed the conclusions drawn from table 1." We first thought they were referring to Omo-Kibish 1, which they both regard as a modern specimen. Because of its similarity to LH 18, we never thought to also use Omo 2 in the comparison. In fact, we avoided both Omo specimens because of their very uncertain contexts and dates.

What, then, is the place of WLH 50 in human evolution? WLH 50 and the Skhul/Qafzeh specimens represent early modern humans, according to Stringer and Bräuer. Their theory requires that these geographically disparate crania should be similar, sharing a number of unique features because of their recent, common origin. In fact, Stringer and Bräuer claim that "metrical comparison of WLH 50 with the early modern Skhul-Qafzeh sample shows an even closer resemblance in shape," citing an unpublished study for its verification. But the idea

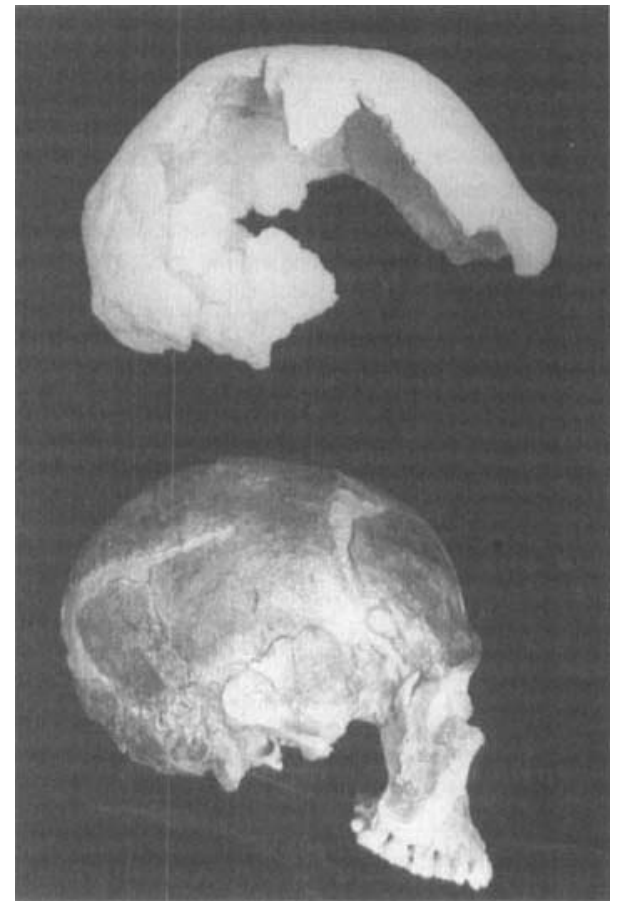

Figure 1

Lateral views of WLH 50 (above) and Qafzeh 9 (below). While considerable variation exists at the Skhul and Qafzeh sites, Qafzeh 9 is the specimen normally used to depict modernity in the Skhul/Qafzeh sample. Like WLH 50, it is a male.

that WLH 50 has any special similarities to the Skhul-Qafzeh hominids (as represented by Qafzeh 9) is easily dispelled by visual inspection of figure 1 . We have not seen the unpublished study they cite, but we are deeply wary of any multivariate analysis that draws relationships that the eye can so easily discount.

Curiously, WLH 50 is forgotten when Stringer and Bräuer examine what they regard as an essential prediction of the Eve theory. In their comment they maintain that they "would also expect (and have observed) that early moderns show a 'less differentiated anatomical form' in the sense that modern regional features were less, or not yet, established." This point cannot be supported with respect to WLH 50 , and it is difficult to conceive of a better refutation of this specific prediction.

Finally, we are at a loss to explain why Stringer and Bräuer (and evidently $\mathrm{Hab}$ good) could not find the zygomaxillary tuberosity on Sangiran 17. Three of us have seen the original specimen and could easily iden- 
tify it, and the structure is clearly present on the cast. Also, since we consider the brows and upper nasal region to be part of the face, we argue for evidence of facial continuity between early and later Australasian groups. Overall, as our critics recognize, features at Ngandong are clearly found in the late Pleistocene of Australia, where, by virtue of their anatomy and behavior, the human populations are modern. This alone proves the Eve theory is incorrect.

\section{North Asia}

Stringer and Bräuer reveal their lack of familiarity with the remains from this important region, although many of their comments cannot be attributed to this problem. For instance, we are criticized for the "unsubstantiated statement" that Zhoukoudian was "continuously inhabited." What we actually said was the site represented "a succession of closely related peoples with local cultural adaptations" (Frayer et al. 1993:20). Gongwangling, which they refer to as the Lantian cranium, is not as "poorly preserved" as the authors maintain. Enough remains so that it is possible to observe that the maxilla is short, the base of the zygomatic process of the maxilla is in a very anterior position, and the upper face is flat. No possible distortion can have affected the expression of these modern Asian features, found in the region's earliest cranium.

Moreover, our emphasis was not just on the features reflecting regional continuity in the pre-Zhoukoudian material but also on material that is both earlier and later. In the later sample, which is much more evenly distributed through the Middle Pleistocene than the Indonesian material, we pointed to the persistent evidence for continuity. We are criticized for discussing this sample because it is older than the replacement time, according to the Eve theory. But if we didn't review this material, we would lose important information indicating continuity and clear morphological links over time in the North Asian sequence, both of which are critical for testing the Eve theory.

The authors further characterize our statement that there are no African features in premodern specimens such as Jinniushan, Dali, and Yunxian as "particularly odd" since these specimens are surely "older than the dispersal event(s)" of modern humans. In fact, Jinniushan may quite possibly date to the same time as the postulated replacement in Europe and Africa (Pope 1992). In China and the rest of the Far East the definite appearance of modern humans comes much later, at least on the basis of our current evidence (but see a discussion of Liujiang in Pope 1992). Yet, if the Eve theory was correct, we surely would expect African features to appear somewhere in the span between levels at Zhoukoudian and Jinniushan, as modern people purportedly invaded China. We cannot be more specific about when the signs for the invasion should appear since, as Stringer and Bräuer must know, neither the expected dates of the invasions nor the dates of the Middle and earlier late Pleistocene sample from China are accurate enough to allow this.

The original framers of the Eve theory specified that the replacement involved only anatomically modern humans, sometime between 200,000 and 50,000 years ago; as Stringer once put it, the modern genes moved because the people carrying them moved. Stringer and Bräuer clearly contend that only modern humans could have accomplished the replacement. What they totally ignore is that specimens reasonably dated to after the "replacement," such as Liujiang, also lack African features, while they do resemble specimens from before the proposed replacement event. Also, they ignore or deny the appearance of modern features in Asia prior to the appearance of (what they regard as clearly identifiable) modern humans. Both claim to see problems in the "archaic/modern transition" in Asia, citing as their basis the fact that key specimens were incomplete and/or distorted. They contend that the Dali face would have been longer if it were reconstructed properly and that the Yunxian specimens are too distorted to be of use. However, the "compressed condition" of Dali, which Stringer and Bräuer refer to, is minimal, and their repeatedly asserting otherwise will never turn it into a Neandertal. The features of the two Yunxian crania, probably not much older than Dali, also demonstrate that numerous modern Chinese features appear before the modern Chinese. They are indeed distorted, but in spite of this, the differences between these specimens and Dali are quite evident. For instance, the faces are relatively massive and show alveolar prognathism. But if distortions and reconstructions cannot prevent the observations of difference, they also cannot prevent the recognition of similarities, as was quite evident in $\mathrm{Li}$ and Etler's (1992) report. A third specimen, the Jinniushan face, is not compressed or distorted. In spite of the condition of these specimens, the North Asian features of a flat zygomatic and horizontally 
oriented inferior zygomaxillary margin are clear in all of them.

Pope (1992) did in fact state that Jinniushan does not fit either complete replacement or an isolated continuity interpretation such as that suggested by Coon (1962). Wolpoff (1985) has made a similar claim for the Hexian remains. These Asian specimens reflect the important role of genic exchanges throughout the course of human evolution and undermine any attempt to show that Asia was somehow isolated from the rest of humanity. Proponents of multiregional evolution base their evolutionary modeling on the persistence of genic exchanges, a contention now clearly supported by the mitochondrial evidence (Templeton 1993). What the anatomical or genetic evidence cannot support is the interpretation of complete lack of admixture in the origin of modern Asians. In the end, we fail to understand how our description of "the variation in and complexity of the Chinese evidence," and indeed of the evidence from other regions, can validly be turned into a disproof of multiregionalism when it is a necessary consequence of the processes underlying our observations.

In their attempt to discredit multiregionalism in North Asia, Stringer and Bräuer restate their assertions that regional continuity in Asia is based on features that are plesiomorphic and/or occur in other regions, often even at higher frequencies. We question whether the phylogenetic approach is relevant in this debate, as it must be based on variable features compared between groups that are not monophyletic in any sense. As for the appearance of Asian features in other regions, Habgood concludes:

The present investigation has, however, demonstrated that there is a combination of at least four morphological features that seem to be indicating a relatively high degree of morphological continuity within the [Australasian] region. [1989:268]

Combination is the key to his claim, as no single feature can be expected to distinguish populations within a polytypic species. Nevertheless, our argument with Stringer and Brảuer is over not these precepts but the data themselves.

In the case of incisor shoveling, Stringer and Bräuer never come to grips with the fact that maxillary incisor shoveling in the known fossil Chinese incisors is still 100 percent. Moreover, it is only by collapsing the data to include expressions of shoveling weaker than ever found in fossil Chinese that the high frequency of more than 70 percent can be obtained from the North African sample. There is no absence of suitably detailed data on shoveling in the literature, and our table 2 (Frayer et al. 1993) is a straightforward presentation of the shoveling data, data that they assert we have never presented. However, as we pointed out, all this may be irrelevant to the issue. Crummett's (1993) reduction of shoveling to three independent anatomical variables provides unambiguous evidence of regionally unique patterns. These will be detailed in her forthcoming dissertation.

Turning to the issue of ear exostoses, Stringer justifies his use of this feature in 1992 by claiming that when he first studied it in 1987, "he could not have anticipated the revised list published by Pope four years later." We are puzzled as to why Stringer was not able to an ticipate their absence from regional continuity discussions in either 1992 or 1987 , since this was based on a widely available article published by Kennedy in 1986 .

Finally, we wonder why the authors, one of whom has been instrumental in convening conferences and editing volumes on new dating techniques and their relevance to human evolution, should now insist that we accept as valid some Chinese dates based on the Uranium/Thorium analysis of teeth (Chen and Zhang 1991). A reference in one of the publications Stringer has edited cautions the reader against doing so (Schwarcz 1992). In fact, the dates we continue to accept as the best available estimates for the Chinese fossils follow Schwarcz's guidelines. We can imagine our critics' comments if we had accepted these dates based on uranium series analysis of teeth.

In sum, what we do not want to see obfuscated by the complexity of this discussion is what any model of the region must account for: (1) the appearance of modern features before modern specimens; (2) the continuity between premodern and modern samples; and (3) the absence of African features in the earliest moderns, or their immediate ancestors. Evidence for all these is inarguably present in the North Asian sequence, and each point refutes the Eve theory.

\section{Europe}

In many ways Europe still presents the most intractable problems in the analysis of local evolution in the late Pleistocene, no doubt because the evolutionary pattern is complex, reflecting changing balances of genic ex- 
change and local selection and/or drift. All the participants in the debate have come to recognize the difficulties of identifying transitions. Part of the problem is that normal variation makes it impossible to identify transitional specimens; but only samples, and not individuals, can be transitional. When we write that Vindija, the focus of most of their criticism, is transitional, the transitional morphology we recognize is represented throughout the sample. Thus while it may be difficult to identify a single fossil as transitional, particularly if it is fragmentary, this is far less of a problem when dealing with a series of specimens that demonstrate a common morphological pattern reflecting intermediacy between earlier and later samples.

It is apparent that the Eve theorists cannot agree on whether there were any transitional samples in Europe. Stringer regards Neandertals as a separate species, but Bräuer identifies the Hahnofersand frontal as the result of (what he calls) hybridization. There are disagreements about transition issues in our camp, also. Smith views the Western European Neandertals as showing "little evidence of evolutionary trends in the modern human direction" (Smith et al. 1989:50), while both Frayer (1992) and Wolpoff (1989) have detailed their claims that such trends were present and significant. We differ to some extent also on the balance envisaged between genic exchanges and local influences oriented by changing selection, in the origin of the postNeandertal populations (compare Frayer 1992 and Smith 1991).

This is misunderstood, however, as Stringer and Bräuer seem to regard Smith's interpretation-namely, that extraneous influence played an important role in the origin of modern Europeans - as a reversal of the argument that the Vindija hominids are transitional. This would be true only if we regarded the origin of modern Europeans an a phenomenon totally independent from the emergence of modern morphology elsewhere. If this is indeed what they think, it reflects a problem we have already discussed-their misunderstanding of multiregional evolution, which stresses regional interconnection rather than isolated in situ regional evolution. Furthermore, they seem to suggest that accepting a role for extraneous influences in the origin of modern human morphology in any region supports their perspectives. However, it is clear, even in this response, that they regard the contribution of non-African archaic humans to modern human gene pools to be relatively minor.
Even for the extreme position within our small group of authors, the contention that extraneous influences probably played a catalytic role in most areas, it has been argued that local contributions were also considered "extensive," even in Europe and Western Asia (Smith 1991:234).

The cause of these difficulties is neither the confusion of hybridization and in situ evolution (which we perceive not as alternatives but as intertwined aspects of the evolutionary process) nor that we are unable to identify which specimens in fragmentary collections are juvenile (the unsubstantiated claim Stringer and Bräuer repeatedly make about the Vindija sample, in spite of the fact that neither has studied the collection). The difficulties are a consequence of the application of the bankrupt type concept. Stringer and Brăuer assume that Neandertals are a type apart from the populations that followed them in time-a different species, according to Stringer. Yet they have dramatically failed to define or describe what makes the morphology of the post-Neandertal populations unique. Stringer's attempts to do so have resulted in a definition for "modern" humans that excludes Holocene Australian fossils (Wolpoff 1986) and living Australians (Brown 1990) from the human species. (We contend that Neandertals are not a type apart in the first place.)

What we find disturbing is the "can't win" position our publications are cast in. For instance, in our group paper in $A A$ and in publications prior to it, for example, Frayer (1992) and Wolpoff (1989) each systematically compared the merits of a European Neandertal versus Skhul/Qafzeh ancestry for the post-Neandertal Europeans. Yet Stringer and Bräuer write that "if there are plausible alternative ancestors for the earliest modern Europeans, such as the Skhul-Qafzeh sample, these should be added in all the relevant comparisons." Yet, after making this claim they admit we did actually put Skhul-Qafzeh into the relevant comparisons, but complain that the sample sizes are too small for them to be meaningful. "The small sample sizes for Africa and Skhul-Qafzeh mean that sampling error could be giving us spurious absence in these groups of a feature." Like us, the reader may wonder which procedure Stringer and Bräuer would have preferred.

In another example we are criticized for including the Vindija 207 mandible in the Upper Paleolithic sample "since this could in fact be a late Neandertal." The specimen was excavated in situ from an early Aurignacian 
layer determined by the apparent association of a split base bone point. If this association is correct, identifying Vindija 207 as a Neandertal would be a disproof of the "Aurignacian $=$ modern assumption" that pervades so many publications (Stringer and Gamble 1993). We could have included it in the Neandertal sample, but then we would have been criticized for assuming that Neandertals made split base bone points typical of the early Aurignacian.

We are accused of using a "double standard" in our assessments of the Vindija and Klasies remains. For example, they chide us for making "the dubious claim that the Klasies frontal 16425 may be immature" and not mentioning that possibility for the "similarly fragmentary Vindija frontal pieces" at the same time. In fact, it was experience gained in trying to separate subadults from adults in the Vindija frontals (Smith and Ranyard 1980; Wolpoff et al. 1981) that led us to the suggestion that the Klasies specimen might be juvenile (see Smith 1992 for further discussion). Indeed, we have always been careful to exclude from comparisons those Vindija specimens that are likely to be juveniles, and the same care applies to the inclusion of the Klasies frontal in comparisons.

We do not believe we are guilty of "misrepresentation of recent research results concerning body proportions." Whatever the explanation for these, there is no evidence of a significant change in these in the post-Neandertal European sequence and a great deal of ambiguity in these for the Near Eastern sample (Frayer 1992). The problem we have with the "heat-adapted ancestry" interpretation of these proportions is that it confuses the underlying cause of the limb proportion-climate relationship with the cause of the Upper Paleolithic Europeans' deviation from it. Generally, deviations have a different explanation than that of the relationship from which they are deviating. Stringer and Bräuer never discuss the fact that if climate were the cause of limb proportion variation in Europe, their "warm adapted Cromagnons" would become cold adapted and their limb proportions and body size would have changed to be more Neandertal-like (or Lapp-like, or Eskimo-like). The fact that they remain stable exposes the invalidity of the Stringer and Bräuer interpretation.

\section{Africa}

Stringer and Bräuer are perhaps most critical of our discussion of the African evidence, a critique that we believe best illustrates the weaknesses of their position. Stringer and Bräuer incorrectly state that we constantly devalue the African evidence compared to that from China and Australia. Actually, we find it critical, as the testing of their model rests on its two necessary predictions that involve Africa: (1) the earliest modern humans will be found in Africa, and (2) the earliest modern humans out of Africa will have African features. They admit to the first, but on the second point their position is less clear. In fact, we are accused of a "serious misrepresentation" on this issue, with Stringer and Bräuer stating that their position is that "the earliest modern humans should resemble their proposed African ancestors ... and not modern Africans." The problem is that we cannot reconcile this with Bräuer's published remark on this issue: "The ancestors of the inhabitants of Europe and Western Asia of some 30,000 years B.P. consisted of modern Africans with some admixture of Neandertals" (1989:139). We have some difficulty also in reconciling it with Bräuer's recent description of the ER 3884 cranium, a specimen that he believes dates to between 100,000 and 500,000 years ago. He describes the specimen as having "features and dimensions that do not fall outside the range of African anatomically modern Homo sapiens" (Bräuer et al. 1992:119). Thus, as we maintained in the initial article, Bräuer seems to agree with Stringer's position that African regional features developed early in the origin of modern humans and before their dispersal.

Most of their commentary is focused on the first point. Our position reflects our firsthand knowledge of the material; our comparative analyses; our reading of Stringer and Andrews (1988a:1266), who describe the African record as "sparser" than other regions; and our acceptance of the cautions that Rightmire $(1979,1984,1986)$ has persistently expressed over the years.

If we seem critical of the dates that are said to support an early appearance of modern humans in Africa, it is because we are concerned about their uncritical acceptance. It is difficult to express more confidence when the Eve theorists themselves cannot decide which dates they believe are correct. Stringer, for instance, attributes a date near 50,000 years ago to Omo 1 (1989:77); but Bräuer (1992:89) declares the correctness of the 130,000-year date, stating "Wolpoff's claim that an age of 40,000 years for Omo 1 is just as sound as a higher age ... contradicts the 
factual situation." We argue that if 40,000 years contradicts the factual situation, 50,000 years cannot be much better. The real problem is that there is no date for Omo Kibish, although, like Border Cave, it surely is Pleistocene.

Beyond the question of dating the material, the bulk of their criticisms are focused on the discussion of the Klasies remains. We made a referencing mistake in citing these authors and Delson for attributing modernity to Djebel Irhoud, Ngaloba, and Florisbad (only Delson has done so). If we seem confused about what Stringer and Bräuer have called them, it may reflect the fact that they are described as "part of an archaic sample that nevertheless shows transitional features" in one place (this commentary), but as standing "close to the threshold to modern humans" (for Florisbad) or "almost at the threshold" (for Ngaloba) in another (Bräuer 1992:87).

Whatever confusion persists about the characterization of these specimens, there is no mistaking Stringer and Bräuer's description of the Klasies sample as a representative of early modern humans. In fact, they quote one of us to this effect, stating that they agree with Smith's contention that "the somewhat primitive aspects of certain features in this sample (particularly in the KRM fossils) ... are to be expected in early representatives of modern humans" (1992:248). They then contend that arguments in Frayer et al. (1993) regarding the nonmodern status of the Klasies specimens represent a contradiction or application of a "double standard." But the quote they cite refers to a sample that includes Border Cave and Omo Kibish 1, which are indeed modern with some archaic features, along with Klasies. Smith (1992:246) has also suggested that the assessment of Klasies morphology has been strongly influenced by the assumption that they are contemporaneous with and part of the same sample as the more modern-appearing Omo 1 and Border Cave specimens. This is consistent with our contention that modernity is a characteristic of samples and not necessarily of individuals (and see Wolpoff and Caspari 1990). Smith further argued that

it is worthwhile to see how well the KRM sample, the only supposedly modern sample firmly dated to around $100 \mathrm{kyr}$, conforms to a modern human pattern without the influence of the possibly younger Omo and Border Cave specimens. [1992:246]

When this is done, the KRM hominids appear more archaic than has generally been ac- knowledged (Smith 1992; Wolpoff and Caspari 1990). Wolpoff and Caspari argue that modernity must be a sample characteristic, and not based on one or two features in isolation, for if it were, there are much better candidates than Klasies for moderns and these come from outside Africa or Western Asia. Therefore, there is no contradiction or double standard in our analysis of the Klasies specimens. We are surprised to find this charge, and we protest its derisive tone, especially with respect to our treatment of Vindija. This is not the first time Bräuer has challenged the transitional nature of the Vindija sample based on his perception of its fragmentation and the potential problems of sex and age distributions (1992:92-93); yet he has never suggested that these same doubts might apply to the assessment of the Klasies hominids.

The characterization of modernity for the Klasies sample is incorrect, in spite of Stringer and Bräuer's attempts to shoehorn the frontal, zygomatic, and mandibles into a modern frame. For the zygomatic they rely on two arguments: (1) the measurement used "is based on a misunderstanding of Martin's measurement $48(3 a)$ " and (2) the size and morphology of the zygomatic can be matched "among recent European material." The Klasies zygomatic is incomplete in that it does not include any of the zygomaxillary suture, although its break is near the suture position. Wolpoff and Caspari (1990) did a comparative analysis of the specimen and provided Smith with an estimated measurement. This was taken from the most medial point preserved on the orbital rim to the most medial point preserved on the lower border of the zygomatic. With the Klasies fragment aligned on other specimens (this is easy to do as the entire frontal pillar, the jugal notch and some temporal process behind it, and the entire inferolateral corner of the orbit border are present), Wolpoff and Caspari found that the closest measurement of zygomatic height that could be taken on complete specimens was Martin 48(3) (the projection of the zygomatic below the Frankfurt Horizontal, as defined by the line connecting the lowest points on the orbital rims). They found also that on the complete specimens, this measurement was always greater than the height measurement that could be taken in the positions (described above) preserved on the Klasies bone. Therefore, the Klasies measurement was considered a minimal estimate. Smith did not discuss these details because he did not foresee that the competence of the researchers 
would be questioned. Beyond this, no amount of argument could negate what visual comparisons so clearly show: the Klasies specimen is larger than any Middle or Upper Pleistocene Sub-Saharan African zygomatic except Bodo. Also, polemics cannot negate indications of other archaic features, such as the frontal pillar detailed by Smith (1992).

Actually, Stringer and Bräuer do not report these comparisons. They do not compare the anatomy or size of the specimen to other Africans, archaic or modern, but choose instead to provide a comparison with recent Europeans. We might consider this to be valid if we were to assume that the Klasies population is ancestral to recent Europeans, but we prefer not to assume the answer to the question we are researching.

Finally, despite their criticisms, we maintain that there are no "transitional sample" mandibles against which to compare the Klasies specimens. The mandibles they claim to be part of the African transitional sample are problematic. Djebel Irhoud 3 is a subadult and should not be compared to adult specimens. The Cave of Hearths mandible is likely older than the range of the transitional sample, based on its archeological associations, similar to Kabwe. The Haua Fteah specimens are essentially fragmentary and provide no meaningful comparisons for the issues debated here. Moreover, Bräuer describes them as part of a "Neandertaloid population" with "strong affinities to Tabun/Shanidar Neanderthaloids in both their metric and nonmetric features" (1984:386). We find his published comments difficult to reconcile with his current assessment that the Haua Fteah mandibles are transitional.

\section{Western Asia}

Stringer and Bräuer criticize our statement that "Skhul and Qafzeh samples ... show no particular resemblances to 'Africans' or to samples from the European Upper Paleolithic" (in reality, what we said was "no unique resemblances"). Since they conclude their discussion with the comment that "it would be wise to remain cautious about specific links," we are unsure why we were criticized to start with. In fact, if we seem confused in our discussions of what Stringer and Bräuer have written on these important sites, compare their assertion that "the Skhul-Qafzeh sample is the most plausible early late Pleistocene ancestral form for early Upper Paleolithic crania," which cites as one of its sources
Stringer (1992a), with Stringer's actual statement:

if the Skhul-Qafzeh hominids are now correctly dated, they seem too ancient to serve as the direct and exclusive ancestors for the earliest $H$. sapiens of Europe. [Stringer 1992a:9]

Their own citation problems are not limited to quotes from their own papers. For instance, in considering Corruccini's (1992) study of the Border Cave 1 and Skhul remains, Stringer and Bräuer accuse us of "double standards" in that we

strangely fail to quote [Corruccini's] agreement with other workers in also finding "no support for the multiregional continuity idea" and no evidence for an ancient origin of modern regional differences [citing Corruccini 1992:444].

In fact, it is not clear that Corruccini agrees with the "other workers" whose views he summarizes in the quoted section of his article. What he says of his study and in his summary of different views is:

The results raise perplexing questions about the interpretation of [the Skhul population and West Asian Neandertals as] two supposedly long-separated species [1992:441] [and] results presented above do not fit the reductionist "out-of-Africa" model and raise anew the perpetual diffculties with the presapiens interpretation of Neandertals (broad sense) and AMHS as separate species. [1992:444]

In another example, Stringer and Bräuer attribute to us the claim that "early modern and Neanderthal specimens were essentially members of the same polytypic population." What we actually said was "the Levant sample as a whole cannot be separated into 'Neandertaloid' and 'modern' sets on either anatomical or behavioral (archeological) grounds." Thus, when they assert that they find this "polytypic population" view unrealistic, they are addressing a straw man (or perhaps a straw population). What they never address is the fundamental point that according to the Eve theory, those hominids must be two different species.

Stringer and Bräuer ask whether there is evidence that early modern humans and Neandertals in the Levant utilized the same stylized burial customs, hunted the same game, and even used the same butchering practices. The last detail was provided byJohn Speth, who has been analyzing faunal material from these sites, and the former two come 
from papers that appeared in volumes edited by Stringer (Bar-Yosef 1992; Shea 1989).

\section{Why Modern Humans?}

From a more general and theoretical perspective, we were intrigued by Stringer and Bräuer's attempts to explain why the dispersing Africans were so dramatically successful. Responding to our observation that there is no evidence for a spreading technological advantage, they suggest an emphasis on the "more general concept of a behavioral advantage, since this could cover innovations in such things as language, cognition, planning depth, and social structure (including reproductive success)" as possible explanations for modern human adaptive advantages that "might not be directly reflected in lithic technology." Yet even such diametrically opposed interpretations of fossil hominid brain evolution such as those of Falk (1987) and Holloway (1983) agree that fossil brain anatomy indicates that language was present by the time humans first left Africa, some 1.2 million years ago if not earlier.

Stringer and Bräuer's other speculations about improved mental abilities and new social structures (with or without reproductive success) remain as conjectures for which there is no evidence at the time of the supposed African migration and replacement. When there is evidence interpreted to show massive behavioral change, European archeologists recognize the problem that the Upper Paleolithic "explosion" occurs long after the appearance of so-called anatomically modern humans. Archeologists in China continue to wrestle with the fact that massive behavioral change never seems to have occurred at all in China, although of course modern humanity is there as well. In neither area can one demonstrate any anatomical change in the brain to coincide with behavioral change. Even Eve theorists such as Harpending and colleagues (1993) now admit that the expansions they can find in past human populations correspond to the spread of modern technology and not modern morphology. The fact remains that proponents of the various replacement scenarios have yet to come up with a viable mechanism to explain wholesale replacement.

\section{Perils and Pitfalls}

Stringer and Bräuer state that changes in mtDNA analysis have occurred too fast to allow comment: "we will not deal with Frayer et al.'s dismissal of mtDNA evidence for ET and RAO because the debate has moved on quickly." This breaches the warning of Stringer and Andrews, who cautioned that "paleoanthropologists who ignore the increasing wealth of genetic data on human population relationships will do so at their peril" (1988a:1268). The genetic consensus that has recently emerged totally dismisses mitochondrial and nuclear DNA as providing any support for an out-of-Africa hypothesis. Templeton's review in $A A$ covered much of this ground, but even some Eve theorists have now questioned the ability of genetics to detect or predict ancient population replacements. For example:

If there was indeed a single large expansion from Africa about 100,000 years ago we should see the signature of it in the mtDNA differences, but instead we see indications of multiple later expansions associated with modern technology instead of modern morphology. [Harpending et al. 1993:495]

It is not surprising Stringer and Bräuer wish to ignore the new developments. The wealth of genetic data not only overturns the Eve theory, it is a clear disproof of the Protsch/ Bräuer "Afro-European sapiens" theory, the "recent African origins" theory, and any other worldwide replacement model involving ancient populations, whatever Stringer and Bräuer may choose to call it.

While it may seem like we have addressed all the contentious issues raised by Stringer and Bräuer, there are a number of others that we have not discussed. In spite of Stringer and Bräuer's remarkable belief that contentions not criticized in our original article are therefore points of agreement ("Frayer et al. limit their detailed criticism to this one point of shoveling. ... We take this to indicate their general recognition that the critique of the Asian and Australian clade features made in Stringer [1992b] is valid"), we will resist refuting many of their other arguments and leave these for our future articles or research by graduate students.

Finally, Bräuer has recently asserted that "supporters of 'Multi-regional Evolution' try to keep their concept alive by making others and probably also themselves believe that their model can still be supported" (1993:403). A similar theme occurs in this reply, and we strongly take issue with its nonscientific implications. Like Weidenreich, we have demonstrated that the replacement or "Eve" theory does not tally with the paleontological facts, and it is not surprising that 
Stringer and Bräuer react so strongly. This is not because our writings reflect inept scholarship, double standards, incompetent science, or poorly conceived epistemology; it is because their theory of modern human origins is wrong, and the facts we have presented show it.

\section{References Cited}

Bar-Yosef, Ofer

1992 The Role of Western Asia in Modern Human Origins. Philosophical Transactions of the Royal Society, Series B 337:193-200.

Bräuer, Günter

1984 A Craniological Approach to the Origin of Anatomically Modern Homo sapiens in Africa and Implications for the Appearance of Modern Europeans. In The Origins of Modern Humans: A World Survey of the Fossil Evidence. Fred H. Smith and F. Spencer, eds. Pp. 327-410. New York: Alan R. Liss.

1989 The Evolution of Modern Humans: A Comparison of the African and NonAfrican Evidence. In The Human Revolution: Behavioural and Biological Perspectives on the Origins of Modern Humans. Paul Mellars and Chris B. Stringer, eds. Pp. 123-154. Edinburgh: Edinburgh University Press.

1992 Africa's Place in the Evolution of Homo sapiens. In Continuity or Replacement? Controversies in Homo sapiens Evolution. Günter Bräuer and Fred $\mathrm{H}$. Smith, eds. Pp. 83-98. Rotterdam: Balkema.

1993 The Origin of Modern Asians: By Regional Evolution or Replacement? In The Evolution and Dispersal of Modern Humans in Asia. T. Akazawa, K. Aoki, and T. Kimura, eds. Pp. 401-413. Tokyo: Hokusen-sha.

Brāuer, Günter, Richard E. Leakey, and Emma Mbua

1992 A First Report on the ER-3884 Cranial Remains from Ileret/East Turkana, Kenya. In Continuity or Replacement? Controversies in Homo sapiens Evolution. G. Bräuer and Fred H. Smith, eds. Pp. 111-120. Rotterdam: Balkema.

Brown, Peter

1990 Osteological Definitions of "Anatomically Modern" Homo sapiens: Tests Using Modern and Terminal Pleistocene Homo sapiens. In Is Our Future Limited by Our Past? L. Freedman, ed. Proceedings of the Third Conference of the
Australasian Society of Human Biology. Pp. 51-74. Nedlands: University of Western Australia.

Chen Tiemei and Zhang Yinyun

1991 Paleolithic Chronology and Possible Coexistence of Homo erectus and Homo sapiens in China. World Archaeology 23:147-154.

Coon, Carleton S.

1962 The Origin of Races. New York: Alfred A. Knopf.

Corruccini, Robert S.

1992 Metrical Reconsideration of the Skhul IV and IX and Border Cave $1 \mathrm{Cra}-$ nia in the Context of Modern Human Origins. American Journal of Physical Anthropology 87:433-445.

Crummett, Tracey L.

1993 Spatial and Temporal Distribution of Shovel-shaping Morphologies. American Journal of Physical Anthropology Supplement 16:76.

Falk, Dean

1987 Hominid Paleoneurology. Annual Review of Anthropology 16:13-30.

Frayer, David W.

1992 Evolution at the European Edge: Neanderthal and Upper Paleolithic Relationships. Préhistoire Européenne 2:9-69.

Frayer, David W., Milford H. Wolpoff, Fred H. Smith, Alan G. Thorne, and Geoffrey G. Pope 1993 The Fossil Evidence for Modern $\mathrm{Hu}$ man Origins. American Anthropologist 95:14-50.

Habgood, Phillip J.

1989 The Origin of Anatomically Modern Humans in Australasia. In The Human Revolution: Behavioural and Biological Perspectives on the Origins of Modern Humans. Paul Mellars and Chris B. Stringer, eds. Pp. 245-273. Edinburgh: Edinburgh University Press.

Harpending, Henry C., S. T. Sherry, Alan R.

Rogers, and Mark Stoneking

1993 The Genetic Structure of Ancient Human Populations. Current Anthropology 34:483-496.

Holloway, R. L.

1983 Human Paleontological Evidence Relevant to Language Behavior. Human Neurobiology 2:105-114.

Kennedy, Gail E.

1986 The Relationship between Auditory Exostoses and Cold Water: A Latitudinal Analysis. American Journal of Physical Anthropology 71:401-416. 
Li T., and Dennis A. Etler

1992 New Middle Pleistocene Hominid Crania from Yunxian, China. Nature 357:404-407.

Pope, Geoffrey G.

1992 Craniofacial Evidence for the Origin of Modern Humans in China. Yearbook of Physical Anthropology 35:243298.

Rightmire, G. Phillip

1979 Implications of the Border Cave Skeletal Remains for Later Pleistocene Human Evolution. Current Anthropology 20:23-35.

1984 Homo sapiens in Sub-Saharan Africa. In The Origins of Modern Humans: A World Survey of the Fossil Evidence. Fred H. Smith and F. Spencer, eds. Pp. 295-325. New York: Alan R. Liss.

1986 Africa and the Origins of Modern Humans. In Variation, Culture, and Evolution in African Populations. R. Singer and J. K. Lundly, eds. Pp. 209-320. Johannesburg: Witwatersrand University Press.

Schwarcz, Henry P.

1992 Uranium-Series Dating and the Origin of Modern Man. Philosophical Transactions of the Royal Society, Series B 337:131-137.

Shea, John J.

1989 A Functional Study of the Lithic Industries Associated with Hominid Fossils from Kebara and Qafzeh Caves, Israel. In The Human Revolution: Behavioural and Biological Perspectives on the Origins of Modern Humans. Paul Mellars and Chris B. Stringer, eds. Pp. 611-625. Edinburgh: Edinburgh University Press.

Smith, Fred H.

1991 The Neandertals: Evolutionary Dead Ends or Ancestors of Modern People? Journal of Anthropological Research 47:219-238.

1992 Models and Realities in Modern Human Origins: The African Fossil Record. Philosophical Transactions of the Royal Society of London, Series B 337:243250.

Smith, Fred H., Anthony B. Falsetti, and

Steven M. Donnelly

1989 Modern Human Origins. Yearbook of Physical Anthropology 32:35-68.

Smith, Fred H., and Gail C. Ranyard

1980 Evolution of the Supraorbital Region in Upper Pleistocene Fossil Hominids from South-Central Europe. American Journal of Physical Anthropology 53:589-610.
Stoneking, Mark, and Rebecca L. Cann

1989 African Origins of Human Mitochondrial DNA. In The Human Revolution: Behavioural and Biological Perspectives on the Origins of Modern Humans. Paul Mellars and Chris B. Stringer, eds. Pp. 17-30. Edinburgh: Edinburgh University Press.

Stringer, Chris B.

1974 Population Relationships of Later Pleistocene Hominids: A Multivariate Study of Available Crania. Journal of Archaeological Science 1:317-342.

1989 The Evolution of Homo Sapiens: An Examination of Patterns in the Fossil Hominid Data. In L'Homme de Néandertal (Extinction). B. Vandermeersch, ed. Pp. 121-127. Liège: ERAUL.

1990 The Emergence of Modern Humans. Scientific American 263(6):98104.

1992a Replacement, Continuity, and the Origin of Homo sapiens. In Continuity or Replacement? Controversies in Homo sapiens Evolution. Günter Bräuer and Fred H. Smith, eds. Pp. 9-24. Rotterdam: Balkema.

1992b Reconstructing Recent Human Evolution. Philosophical Transactions of the Royal Society, Series B 337:217-224.

1993 New Views on Modern Human Origins. In The Origin and Evolution of Humans and Humanness. D. T. Rasmussen, ed. Pp. 75-94. Boston: Jones and Bartless.

Stringer, Chris B., and Peter Andrews

1988a Genetics and the Fossil Evidence for the Origin of Modern Humans. Science 239:1263-1268.

1988b Modern Human Origins. Science 241:773-774.

Stringer, Chris B., and Clive Gamble

1993 In Search of the Neanderthals. London: Thames and Hudson.

Templeton, Alan R.

1993 The "Eve" Hypothesis: A Genetic Critique and Reanalysis. American Anthropologist 95:51-72.

Weidenreich, Franz

1940 Some Problems Dealing with Ancient Man. American Anthropologist 42:375-383.

Wolpoff, Milford $\mathrm{H}$.

1985 Human Evolution at the Peripheries: The Pattern at the Eastern Edge. In Hominid Evolution: Past, Present, and Future. Proceedings of the Taung Diamond Jubilee International Symposium. 
P. V. Tobias, ed. Pp. 355-365. New York: Alan R. Liss, Inc.

1986 Describing Anatomically Modern Homo sapiens: A Distinction without a Definable Difference. In Fossil Man: New Facts, New Ideas. Papers in Honor of Jan Jelínek's Life Anniversary. V. V. Novotny and A. Mizerov, eds. Anthropos (Brno) 23:41-53.

1989 The Place of the Neandertals in $\mathrm{Hu}$ man Evolution. In The Emergence of Modern Humans. Biocultural Adaptations in the Later Pleistocene. Erik Trinkaus, ed. Pp. 97-141. Cambridge: Cambridge University Press.

Wolpoff, Milford H., and Rachel Caspari 1990 On Middle Paleolithic/Middle Stone Age Hominid Taxonomy. Current Anthropology 31:394-395.
Wolpoff, Milford H., Fred H. Smith, Mirko Malez, Jakov Radovcic, and Darko Rukavina 1981 Upper Pleistocene Human Remains from Vindija Cave, Croatia, Yugoslavia. American Journal of Physical Anthropology 54:499-545.

Wolpoff, Milford H., James N. Spuhler, Fred H. Smith, Jakov Radovcic, Geoffrey Pope, David W. Frayer, Robert Eckhardt, and Geoffrey Clark 1988 Modern Human Origins. Science 241:772-773.

Wolpoff, Milford H., Wu Xinshi, and Alan G. Thorne

1984 Modern Homo sapiens Origins: A General Theory of Hominid Evolution Involving the Fossil Evidence from East Asia. In The Origins of Modern Humans: A World Survey of the Fossil Evidence. Fred H. Smith and F. Spencer, eds. Pp. 411-483. New York: Alan R. Liss. 